University of Nebraska - Lincoln

DigitalCommons@University of Nebraska - Lincoln

Faculty Publications in Computer \& Electronics Electrical \& Computer Engineering, Department Engineering (to 2015)

2012

\title{
Dynamic Reconfigurable Multi-Cell Battery: A Novel Approach to Improve Battery Performance
}

\author{
Song $\mathrm{Ci}$ \\ University of Nebraska-Lincoln, sci2@unl.edu \\ Jiucai Zhang \\ University of Nebraska-Lincoln, jczhang@huskers.unl.edu \\ Hamid Sharif \\ University of Nebraska-Lincoln, hsharif@unl.edu \\ Mahmoud Alahmad \\ University of Nebraska-Lincoln, malahmad2@unl.edu
}

Follow this and additional works at: https://digitalcommons.unl.edu/computerelectronicfacpub

Part of the Computer Engineering Commons

Ci, Song; Zhang, Jiucai; Sharif, Hamid; and Alahmad, Mahmoud, "Dynamic Reconfigurable Multi-Cell Battery: A Novel Approach to Improve Battery Performance" (2012). Faculty Publications in Computer \& Electronics Engineering (to 2015). 73.

https://digitalcommons.unl.edu/computerelectronicfacpub/73

This Article is brought to you for free and open access by the Electrical \& Computer Engineering, Department of at DigitalCommons@University of Nebraska - Lincoln. It has been accepted for inclusion in Faculty Publications in Computer \& Electronics Engineering (to 2015) by an authorized administrator of DigitalCommons@University of Nebraska - Lincoln. 


\title{
Dynamic Reconfigurable Multi-Cell Battery: A Novel Approach to Improve Battery Performance
}

\author{
Song Ci, Jiucai Zhang, Hamid Sharif, and Mahmoud Alahmad* \\ Department of Computer and Electronics Engineering University of Nebraska-Lincoln, NE 68182, USA \\ *Department of Architecture Engineering University of Nebraska-Lincoln, NE 68182, USA \\ sci2@unl.edu, jczhang@huskers.unl.edu, and \{hsharif, malahmad2\}@unl.edu
}

\begin{abstract}
Many electronic systems such as robotics, batterypowered electric vehicles, and mobile computing devices are powered by multi-cell battery with limited energy capacity. Therefore, maximizing the battery performance such as operating time, available capacity, and lifetime is one of the major battery design challenges. Traditional approaches such as dynamic power management to maximize the battery discharge performance have treated multi-cell battery as a pure passive component with a fixed configuration. Thus, the multi-cell battery performance is determined by the weakest battery cell, leading to a low utilization of battery energy. In this paper, we propose a novel multi-cell battery design to dynamically reconfigure the cell topology of a multi-cell battery, which also interacts with the power management module of a battery-powered system to maximize the battery discharge performance. Then, the dynamic reconfiguration problem of the multi-cell battery is formulated as a Lagrangian Relaxation problem and solved by dynamic programming. Both simulation and experimental results show that the proposed design can significantly enhance the multicell battery operating time and useable capacity. Moreover, the proposed design can automatically exclude the failure or malfunction cells through reconfiguration, which can greatly improve the multi-cell battery safety.
\end{abstract}

\section{INTRODUCTION}

To provide the high voltage and high capacity battery power supply, multiple battery cells are commonly encased within a protective pack in a fixed configuration, which contains sensors to monitor and measure cell properties. As a result, all cells are equally treated, which are charged or discharged simultaneously. However, the system power management module overseeing a multi-cell battery makes decisions on discharge terminal based on the weakest cell measurement, ignoring the fact that other cells may be still capable of providing additional usable capacity.

Considering dynamic reconfiguration into the multi-cell battery will provide more scalability, dependability, and fault tolerance, and in turn improve the battery performance. However, the reconfiguration capability of the multi-cell battery is very limited. In [1], an N+ Switch Array Matrix topology has been developed to provide the reconfiguration capability to selectively connect and isolate individual battery cell. In [2], multi-cell battery dynamic reconfiguration concept has been introduced to improve the battery operating time and capacity, respectively. In [3], multi-cell battery configuration is changed from series to parallel and vice versa to improve the efficiency of the DC-DC converter. In [4], cells in the multi-cell battery

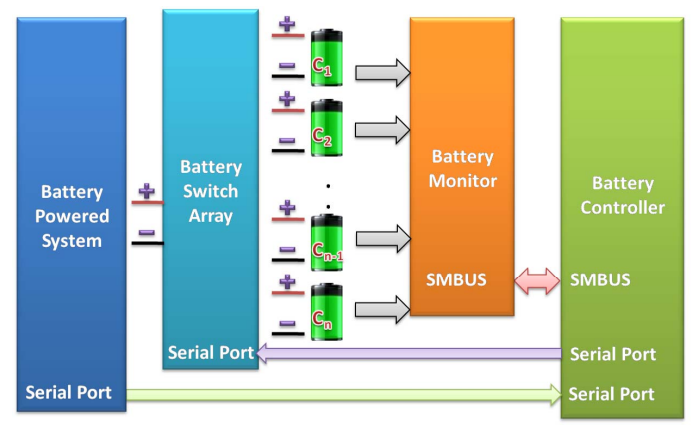

Fig. 1. The diagram of the proposed multi-cell battery design

are divided into banks, and then an offload schedule method is adopted to select cell in each bank to enhance the operating time and safety. Due to the limited reconfiguration capability, these methods can only partially solve the problem and provide suboptimal results.

In this paper, we propose a novel dynamic reconfigurable multi-cell battery design to improve battery performance. Based on the current battery status and the load request posed by the system power management module, the proposed design will dynamically select the optimal cell configuration to minimize system power consumption and maximizing battery capacity and operating time. Furthermore, the proposed design can provide multiple voltage levels, which may improve the battery scalability and reduce the complexity of DC-DC circuitry. Through dynamic reconfiguration, the proposed battery design can exclude faulty cells from battery power supply to enhance the battery dependability and safety issues.

\section{The Proposed Multi-Cell BAttery Design}

Figure 1 shows an overview of the proposed multi-cell battery design. The key components of the proposed design are adaptive battery controller and battery switch array. The battery controller predicts battery performance such as state of charge (SOC), state of health ( $\mathrm{SOH})$, voltage, and internal resistance based on various battery operation conditions. Based on the predicted performance as well as the load posed by the system power management module, battery cells will be dynamically reconfigured via the battery switch array. The battery switch array is shown in Figure 2, where each cell uses 6 switches to parallel, series, and exclude itself with/from the 


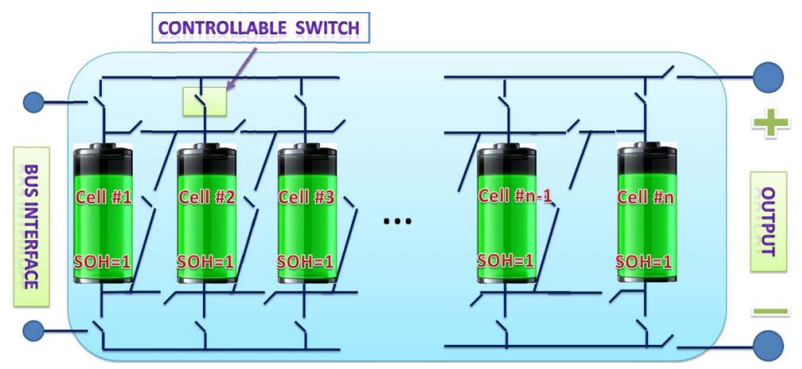

Fig. 2. Battery switch array

other cells. The connectivity of these cells can be expressed as a configuration matrix:

$$
C=\left(\begin{array}{ccc}
S_{11} & \ldots & S_{1 N} \\
\vdots & \ddots & \vdots \\
S_{61} & \ldots & S_{6 N}
\end{array}\right)
$$

where, $S_{i j}$ indicates the switch state of $i^{t h}$ switch of $j^{\text {th }}$ battery cell, whose value could be denoted as:

$$
S_{i j}= \begin{cases}1 & \text { on } \\ 0 & \text { off }\end{cases}
$$

\section{PRoblem Formulation}

Recall the design goal is to improve the multi-cell battery performance and prolong battery operating time under a given load posed by system power management module. Assuming that the duration of the load is $d$, which can be further divided into $N$ time intervals $T=\frac{d}{N}$. At the beginning of each time interval, the adaptive reconfiguration process will be triggered. Therefore, the formulated problem turns into maximizing the usable battery capacity over $d$ under the given load request by choosing the optimal configuration at the beginning of each time interval $T$. The path graph of the dynamic reconfiguration process of a multi-cell battery is shown in Figure 3, where, $K$ is the total number of configurations of a multi-cell battery with $n$ cells, and $N$ is the total number of intervals (stages). Each state $C^{i},(i=0,1, \ldots, K)$ corresponds to a feasible configuration (actions) under the current cell status in terms of SOH and SOC, which can be denoted as a configuration set $\mathcal{C}=\left\{C^{1}, C^{2}, \cdots, C^{K}\right\}$. Each arc $\gamma_{i j}^{m}$ is associated a cost value, which is the expected consumed SOC of a multi-cell battery at the $m^{\text {th }}$ time interval when cells are reconfigured from configuration (action) $C^{i}$ to configuration (action) $C^{j}$, where $i, j=1,2, \ldots, K$. Assuming that $\Pi=$ $\left\{C_{1}, C_{2}, \cdots, C_{N}\right\}\left(C_{i} \in \mathcal{C}\right.$, and $\left.i=1,2, \cdot, N\right)$ is applied configurations for $N$ internals. Consequently, the cost-to-go function $G(\Pi)$ is to optimally choose applied configurations $\Pi$ to minimize the attainable sum of expected capacity, which can be denoted as:

$$
\begin{gathered}
G_{N}(\Pi)=\min \sum_{j=0, C_{j} \in \mathcal{C}}^{N} \gamma_{j}\left(\varphi_{j}^{B}\left(I_{j}^{B}, C_{j}, h, T\right), C_{j}\right) \\
\text { subject to: } \\
\left\{\begin{array}{l}
V_{j}^{B}\left(\varphi_{j}^{B}\left(I_{j}^{B}, C_{j}, h, T\right), C_{j}\right) \geq V_{r} \\
I_{j}^{B}=I_{r}
\end{array}\right.
\end{gathered}
$$

where, $\varphi_{j}^{B}, \gamma_{j}, C_{i}$, and $V_{j}^{B}$ are SOC, consumed SOC, and battery configuration, and voltage of multi-cell battery at the $i^{\text {th }}$ time interval, which can be obtained by multi-cell battery model in [5], [6]. $h$ is the $\mathrm{SOH}$ of multi-cell battery.

\section{Problem Solution}

The Lagrangian relaxation method leads to a convex hull approximation of the formulated constrained problem in Eq. (3). We first define a Lagrangian cost function:

$$
\begin{aligned}
& J_{\lambda_{1}, \lambda_{2}}(\Pi)=\sum_{j=0, C_{j} \in \mathcal{C}}^{N}\left\{\gamma_{j}\left(\varphi_{j}^{B}\left(I_{j}^{B}, C_{j}, h, T\right), C_{j}\right)+\right. \\
& \left.\lambda_{1}\left(I_{r}-I_{j}^{B}\right)+\lambda_{2}\left(V_{r}-V_{j}^{B}\left(\varphi_{j}^{B}\left(I_{j}^{B}, C_{j}, h, T\right), C_{j}\right)\right)\right\}
\end{aligned}
$$

where $\lambda_{1}$ and $\lambda_{2}$ are the Lagrange multipliers. If there exists $\lambda_{1}^{*}$ and $\lambda_{2}^{*}$ such that $\Pi^{*}=\arg \left[\operatorname{Min}_{\Pi} J_{\lambda_{1} \cdot \lambda_{2}}(\Pi)\right]$ leads to $I_{j}^{B}=$ $I$ and $V_{j}^{B} \geq V_{r}$, then $\Pi^{*}$ is also an optimal solution to the problem in Eq. (3). Therefore, the task to solve Eq. (3) is equivalent to the easier task of finding the optimal solution to the unconstrained problem

$$
\begin{aligned}
\min & \sum_{j=0, C_{j} \in \mathcal{C}}^{N}\left\{\gamma_{j}\left(\varphi_{j}^{B}\left(I_{j}^{B}, C_{j}, h, T\right), C_{j}\right)+\lambda_{1}\left(I_{r}-I_{j}^{B}\right)\right. \\
& \left.+\lambda_{2}\left(V_{r}-V_{j}^{B}\left(\varphi_{j}^{B}\left(I_{j}^{B}, C_{j}, h, T\right), C_{j}\right)\right)\right\}
\end{aligned}
$$

which is essentially a dynamic programming problem, and can be solved by the method as in [7].

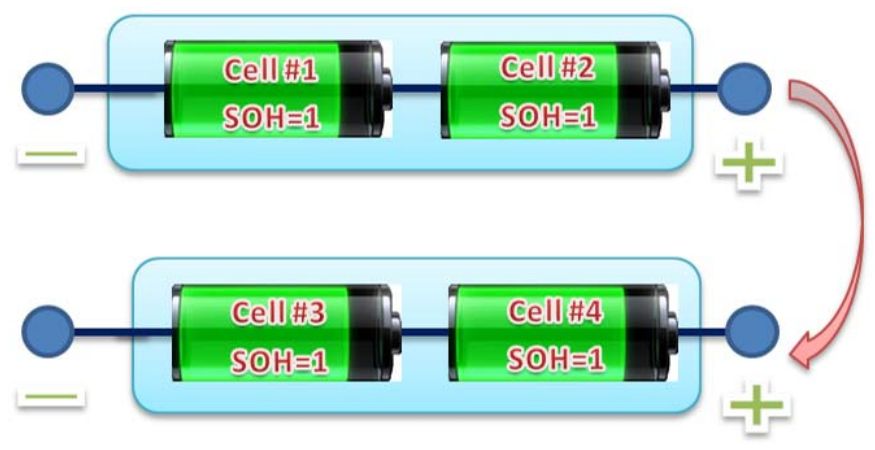

Fig. 3. Typical multi-cell battery configuration

\section{EXPERIMENT RESUlts}

To show the performance improvement of the proposed multi-cell battery system, we conducted experiment on the traditional battery topology with four cells as shown in figure 4 (a) and the proposed multi-cell battery design as shown in figure 4 (b). System required voltage and current are $6 \mathrm{~V}$ and $1 A$, respectively. All cells in both multi-cell battery are 


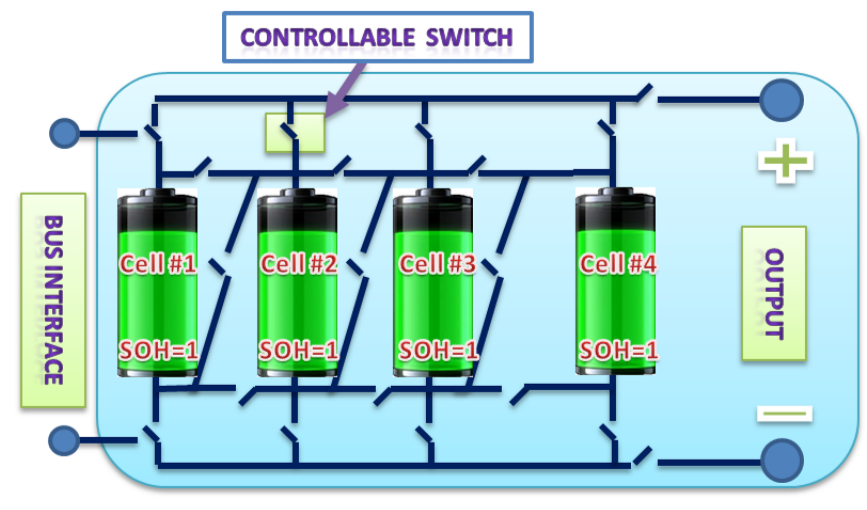

Fig. 4. Proposed multi-cell battery configuration

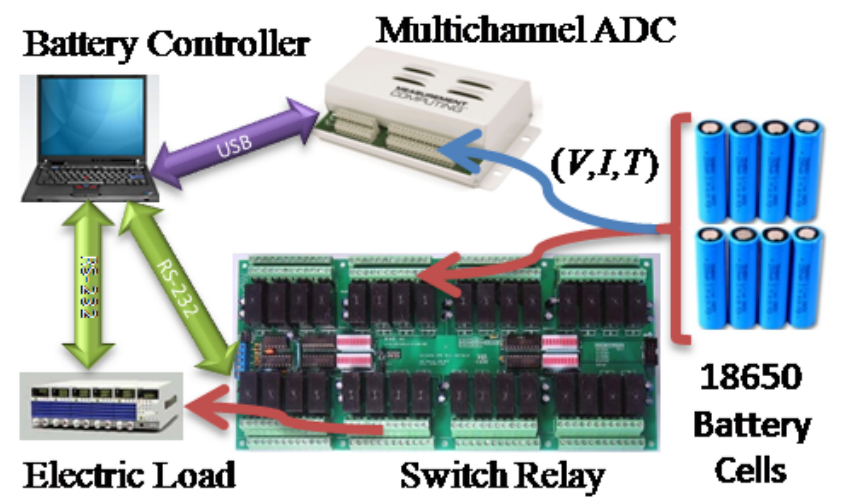

Fig. 5. The schematic of prototype

HE18650 [8], whose cutoff voltages and capacity are $3 \mathrm{~V}$ and $2600 m A h$, respectively.

We have conducted the experiments on the prototype system as shown in Figure 5, which consists of a laptop, a relay array (R3210PROXR RS232 Relay) [9], a multi-channel ADC (USB-1616FS) [10], multiple battery cells (LC-18650H4tab) [8], and an electric load [11]. The multi-channel ADC acquires states of multi-cell battery and each cell such as the output voltage, current and temperature. The laptop is used as a battery controller to optimize the multi-cell battery configuration. The electric load is employed to simulate the load posed by the dynamic power management module of a battery-powered system.

Figure 6 shows the experiment results. We can observe that the proposed design can significantly prolong the battery operating time than the traditional fixed-configuration design. The operation time of the typical multi-cell battery is 14110 seconds and the operating time of the proposed multi-cell battery is 17160 seconds, meaning that the operating time has been improved about $21.6 \%$ by the proposed design.

\section{CONCLUSION}

In this paper, a novel multi-cell battery design is proposed. The proposed design will dynamically reconfigure the multicell battery to achieve the optimal battery discharge per-

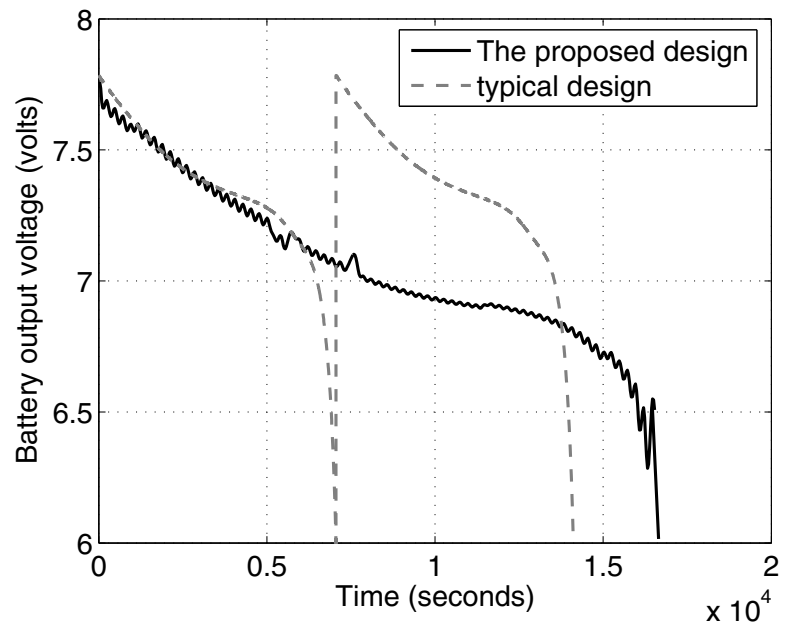

Fig. 6. Experiment results

formance. The experimental results show that the proposed design can significantly improve the battery operating time. Compared with the traditional multi-cell battery system, the operating time is improved about $21.6 \%$. In addition, the proposed multi-cell battery system can also exclude the faulty cells from the battery power supply circuitry and greatly improve the multi-cell battery safety.

\section{ACKNOWLEDGEMENTS}

This research was supported in part by NSF ECCS grant No. 0801736.

\section{REFERENCES}

[1] M. Alahmad and H. Hess, "Reconfigurable topology for jpls rechargeable micro-scale batteries," in 12th NASA Symposium on VLSI Design, Coeur dAlene, Idaho, USA, 2005, pp. 4-5.

[2] S. Ci, J. Zhang, M. Alahmad, and H. Sharif, "A Novel Design of Adaptive Reconfigurable Multicell Battery for Power-Aware Embedded Networked Sensing Systems," in IEEE Global Telecommunications Conference, Washington, DC, USA, 2007, pp. 1043-1047.

[3] H. Visairo and P. Kumar, "A reconfigurable battery pack for improving power conversion efficiency in portable devices," in the 7th International Caribbean Conference on Devices, Circuits and Systems, Cancun, Mexico, April 2008, pp. 1-6.

[4] S. K. Mandal, P. S. Bhojwani, S. P. Mohanty, and R. N. Mahapatra, "Intellbatt: Towards smarter battery design," in 45th ACM/IEEE Design Automation Conference, Anaheim, CA, USA, June 2008, pp. 872-877.

[5] J. Zhang, S. Ci, H. Sharif, and M. Alahmad, "Modeling discharge behavior of multicell battery," IEEE Transations on Energy Conversion, vol. 25, no. 4, pp. 1133-1141, 2010.

[6] J. Zhang, S. Ci, H. Sharif, and M.Alahmad, "An enhanced circuit based battery model for single-cell battery," in IEEE Applied Power Electronics Conference and Exposition, 2009, pp. 1635-1639.

[7] L. O. Chua and G. N. Lin, "Nonlinear programming without computation," IEEE Transactions on Circuits and Systems, vol. 31, no. 2, pp. 182-188, 1984.

[8] Powerizer, Li-Ion 18650 Cylindrical Cell-LC-18650H4. [Online]. Available: http://www.batteryspace.com/index.asp?PageAction= VIEWPROD\&ProdID $=2763$

[9] NCD, 32-Channel 5A DPDT Serial Relay Controller with XR Expansion Port, National Control Devices. [Online]. Available: http://www.controlanything.com/Merchant $2 /$ merchant.mvc?Screen= PROD\&Product_Code=R325DPDTPROXR\&Category_Code=CAT_ RELAY32_DPDT 
[10] MCC, 16 channel, 16-bit, simultaneous sampling, USB based analog and digital $I / O$ device, Measurement Computing Corporation. [Online]. Available: http://www.measurementcomputing.com/ cbicatalog/cbiproduct_new.asp?dept_id=413\&pf_id=1666\&mscssid= EK29WQAGKAT08LESCTA23FNCVMF60968

[11] KIKUSUI, PLZ-U-50F Modular Multifunction DC Electronic Load, KIKUSUI AMERICA, INC. [Online]. Available: http://db.kikusui.co. $\mathrm{jp} / \mathrm{fmi} / \mathrm{xsl} / \mathrm{kai} 2 /$ detail.xsl?\&IdFamily $=0010$ 